\title{
PONTOS REFERENCIAIS NOS ACESSOS CRANIANOS
}

\author{
Sebastião Gusmão, Roberto Leal Silveira, Aluízio Arantes
}

\begin{abstract}
RESUMO - O conhecimento da topografia cranioencefálica permite delimitar os acessos cranianos. Sistematizase os pontos referenciais, definidos em relação aos pontos craniométricos, usados nos diferentes acessos cranianos. Dos 22 pontos referenciais descritos, os doze primeiros estão em relação com a base do crânio e os demais com a convexidade.
\end{abstract}

PALAVRAS-CHAVE: topografia cranioencefálica, acessos neurocirúrgicos.

\begin{abstract}
Landmarks to the cranial approaches
ABSTRACT - The knowledge of the craniotopography allows the delimitation of the cranial approaches. In this study the landmarks, defined in relation to the craniometric points and used in the different cranial approaches, were systematized. Twenty two landmarks are described: the first twelve are in relation to the skull base and the remainder are in relation to the skull vertex.
\end{abstract}

KEY WORDS: craniotopography, neurosurgical approaches.

Em decorrência da especialização funcional das diferentes áreas do encéfalo e do rígido estojo ósseo que o protege, o acesso à cavidade craniana deve ser definido com precisão e constitui parte fundamental do procedimento cirúrgico. A topografia cranioencefálica (relação da convexidade craniana com a superfície do encéfalo) é requisito fundamental para orientar os diferentes acessos à cavidade craniana. O tempo despedido na cuidadosa delimitação do acesso é altamente recompensador, pois um procedimento cirúrgico simples pode tornar-se difícil e sujeito a complicações pelo posicionamento incorreto da craniotomia. O neurocirurgião deve visualizar a área da superfície cortical subjacente ao orifício de trépano e localizar os orifícios de tal forma que o alvo cirúrgico fique colocado no centro da craniotomia.

A correta orientação para abordagem neurocirúrgica inicia-se pela identificação de referências anatômicas superficiais, conhecidas como pontos craniométricos, e, a partir dos mesmos, define-se os pontos referenciais para o acesso craniano. Os principais pontos craniométricos são: násio, glabela, bregma, lambda, ínio, ptério, stefânio, astério, pório e apófise orbitária externa. Os pontos referenciais da convexidade são, geralmente, a projeção sobre o crânio de pontos dos principais sulcos da face súperolateral do cérebro; os pontos referenciais da base definem os locais preferenciais para a colocação dos orifícios de trépano nos acessos à base do crânio. 0 objetivo do presente estudo é sistematizar os pontos referenciais nos acessos cranianos. Dos 22 pontos referenciais descritos, os doze primeiros estão em relação com a base do crânio e os demais com a convexidade.

1. Ponto frontobasal ântero-medial (Fig 1,2) Localiza-se no násio ou ângulo frontonasal (ponto mediano da sutura frontonasal) e corresponde, internamente, ao extremo anteromedial da fossa anterior (crista galli), onde se assentam as extremidades anteriores dos pólos frontais. O orifício de trépano perfurado imediatamente acima do násio, sobre a glabela (área situada entre as duas cristas superciliares, correspondente à porção medial do seio frontal), faz parte dos acessos frontobasal anterior, subfrontal e fronto-orbital ou supraorbital para abordagem da região medial da fossa anterior.

\section{Ponto frontobasal médio ou superciliar (Fig} $1,2)$ - Este ponto localiza-se imediatamente acima do rebordo orbitário superior, entre o násio e a apófise orbitária externa (processo zigomático do osso frontal). Nele é colocado o segundo orifício de trépano do acesso fronto-têmporo-esfenoidal ou pterional' ${ }^{1}$. Subjacente a este orifício encontra-se a borda superciliar do hemisfério cerebral.

\footnotetext{
Laboratório de Microcirurgia da Faculdade de Medicina da Universidade Federal de Minas Gerais (UFMG), Serviço de Neurocirurgia do Hospital Madre Teresa e Serviço de Neurocirurgia do Hospital Luxemburgo, Belo Horizonte MG, Brasil. 


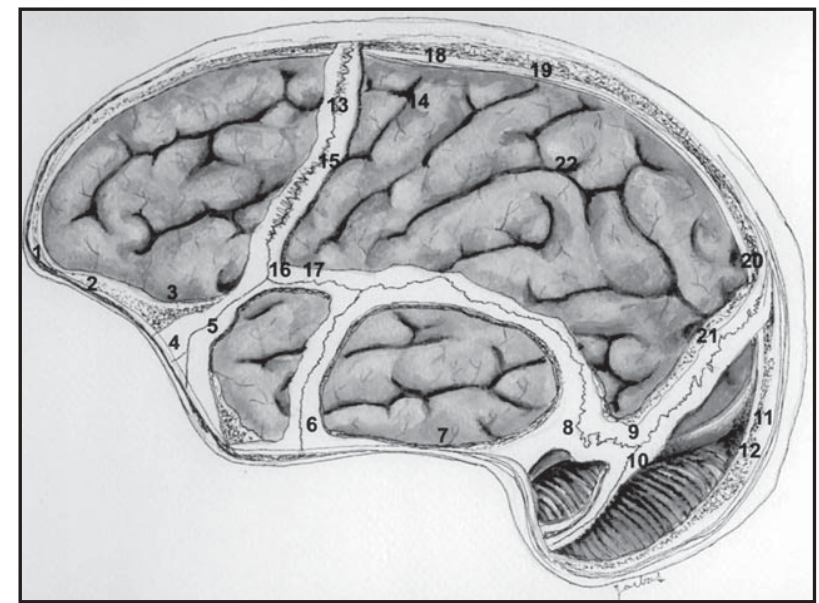

Fig 1. Esquema das suturas do crânio e da superfície lateral do encéfalo para mostrar os pontos referenciais nos acessos cranianos. Os números referem-se à numeração dos pontos no texto: 1- frontobasal ântero-medial; 2- frontobasal médio ou superciliar; 3-frontobasal póstero-medial; 4- fronto-orbital; 5- esfenoidal ou frontotemporal; 6- temporobasal anterior; 7- temporobasal médio; 8- temporobasal posterior; 9- pré-occipital; 10- retrossigmóideo; 11 - paratorcular superior; 12- paratorcular inferior; 13- ponto de interseção do sulco frontal superior e da sutura coronária ou ponto para punção do corno frontal; 14- ponto de junção dos sulcos frontal superior e pré-central; 15- ponto de união dos sulcos frontal inferior e pré-central ou do stefânio; 16coronal inferior; 17- inferior do sulco central; 18- superior do sulco pré-central; 19- superior do sulco central; 20-parieto-occipital; 21 - ponto para punção do corno occipital; 22-intraparietal.

3. Ponto frontobasal póstero-lateral (Fig 1,3) Este ponto encontra-se logo atrás da apófise zigomática do osso frontal, no pequeno abaulamento triangular da região frontal lateral, denominado de face temporal do frontal. Este abaulamento corresponde internamente à fossa onde se aloja a parte orbital do giro frontal inferior, localizada na parte póstero-lateral da fossa anterior, lateralmente ao teto da órbita ${ }^{2-4}$. No ponto frontobasal posterolateral é perfurado o primeiro orifício de trépano do acesso pterional ${ }^{1}$.

4. Ponto fronto-orbital (Fig 1,3) - No acesso órbito-frontal ou supraorbitário, o orifício de trépano localizado junto à união das suturas frontozigomática, fronto-esfenoidal e esfenozigomática (ponto fronto-orbital), dá acesso simultaneamente à base da fossa anterior e à órbita, ficando as duas cavidades separadas pelo teto da órbita².

\section{Ponto esfenoidal ou frontotemporal (Fig 1,} 3) - A face externa da asa maior do osso esfenóide apresenta uma concavidade no sentido antero-posterior, que corresponde à junção das superfícies articulares do osso frontal e da asa maior do esfenóide,

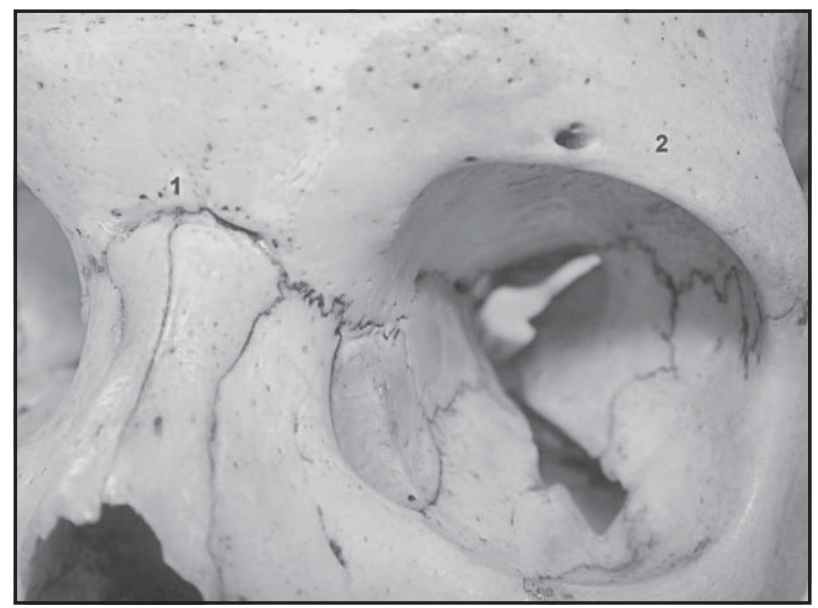

Fig 2. Região anterior do crânio. Os números referem-se à numeração dos pontos no texto: 1- frontobasal ântero-medial; 2frontobasal médio ou superciliar.

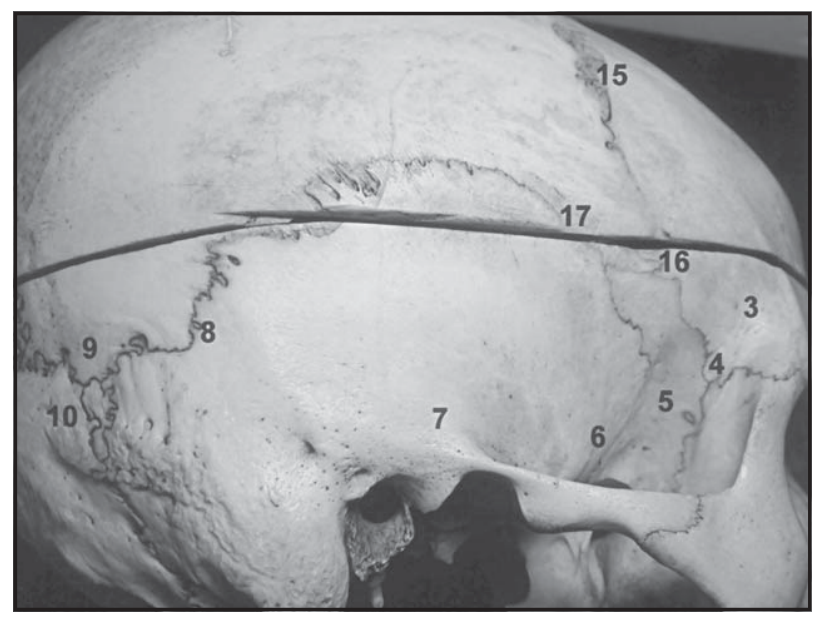

Fig 3. Região lateral do crânio. Os números referem-se à numeração dos pontos no texto: 3-frontobasal póstero-medial; 4- frontoorbital; 5- esfenoidal ou frontotemporal; 6- temporobasal anterior; 7- temporobasal médio; 8- temporobasal posterior; 9- préoccipital; 10- retrossigmóideo; 15 - ponto de união dos sulcos frontal inferior e pré-central ou do stefânio; 16- coronal inferior; 17- inferior do sulco central.

limite entre as fossas anterior e média. Em uma variação da colocação dos orifícios de trépano no acesso pterional, o orifício de trépano localizado nesta concavidade, ao nível da sutura frontozigomática (ponto esfenoidal ou frontotemporal), expõe as fossas anterior e média.

6. Ponto temporobasal anterior (Fig 1, 3) - Localiza-se na porção inferior da sutura têmporo-esfenoidal e o orifício de trépano sobre este ponto expõe a porção anterior da fossa média. Corresponde ao quarto orifício da craniotomia pterional'. 


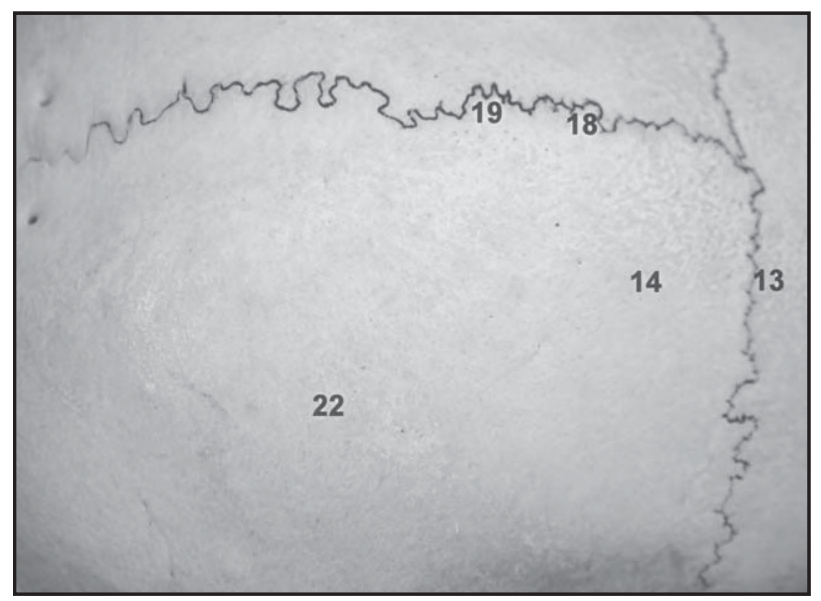

Fig 4 . Região superior do crânio. Os números referem-se à numeração dos pontos no texto: 13- ponto de interseção do sulco frontal superior e da sutura coronária ou ponto para punção do corno frontal; 14- ponto de junção dos sulcos frontal superior e pré-central; 18- superior do sulco pré-central; 19- superior do sulco central; 22- intraparietal.

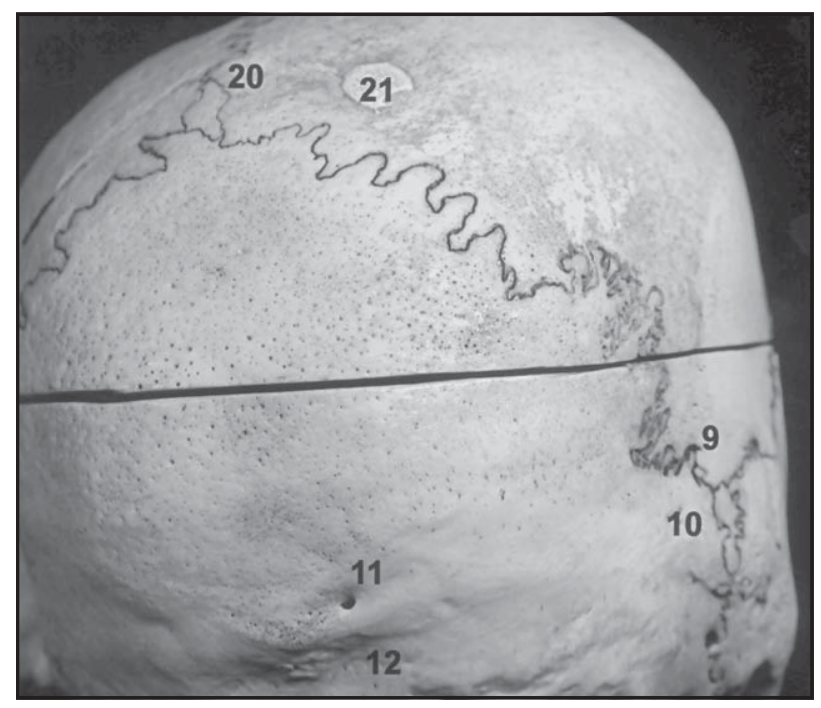

Fig 5 . Região posterior do crânio. Os números referem-se à numeração dos pontos no texto: 9- pré-occipital; 10- retrossigmóideo; 11 - paratorcular superior; 12- paratorcular inferior; 20-parieto-occipital; 21 - ponto para punção do corno occipital.

7. Ponto temporobasal médio (Fig 1, 3) - Encontra-se imediatamente acima da raiz posterior do arco zigomático, logo à frente do pório (pólo superior do meato acústico externo). Internamente corresponde à extremidade anterior da porção petrosa do osso temporal e à emergência da artéria meníngea média.

8. Ponto temporobasal posterior (Fig 1, 3) - A união das suturas parietomastóidea e escamosa corresponde ao ponto mais lateral da borda superior da pirâmide petrosa, marcando, portanto, o limite entre o assoalho da fossa média e o início da tenda do cerebelo. $O$ orifício de trépano localizado imediatamente acima da união destas suturas (ponto temporobasal posterior) dá acesso à extremidade posterior da fossa média (acesso temporobasal) ${ }^{3,4}$. A craniotomia temporobasal delimitada entre os pontos temporobasais médio e posterior expõe a face superior da porção petrosa do osso temporal e corresponde intracranialmente ao giro fusiforme e ao tronco encefálico.

9. Ponto pré-occipital (Fig 1, 3, 5) - Este ponto localiza-se sobre a sutura lambdóide, $1 \mathrm{~cm}$ acima do astério (ponto de união das suturas parietomastóidea, lambdóide e occipitomastóide). Corresponde à incisura pré-occipital, marcando, portanto, o limite entre os lobos temporal e occipital na borda ínferolateral do hemisfério ${ }^{4,5}$. A linha que liga o ponto préoccipital (correspondente à incisura pré-occipital) ao ponto localizado $10 \mathrm{~mm}$ à frente de lambda (ponto parieto-occipital, correspondente ao sulco parietooccipital e descrito à frente) marca o limite ânterolateral do lobo occipital e da craniotomia occipital.

10. Ponto retrossigmóideo (Fig 1, 3, 5) - O astério relaciona-se com a extremidade distal do sulco do seio transverso, estando mais freqüentemente junto a sua margem inferior ${ }^{4}$. O orifício de trépano localizado imediatamente abaixo do astério (ponto retrossigmóideo) dá acesso à região lateral da fossa posterior (acesso suboccipital retrossigmóideo) no ângulo formado pela transição dos seios transverso e sigmóide.

11. Ponto paratorcular superior (Fig 1, 5) - Localiza-se imediatamente superior e lateral ao ínio (ápice da protuberância occipital externa). Internamente corresponde ao ângulo formado pela união dos seios sagital superior e transverso, onde se aloja a extremidade do pólo occipital. Nele é colocado o orifício de trépano inferomedial da craniotomia occipital.

12. Ponto paratorcular inferior (Fig 1, 5) - Localiza-se imediatamente inferior e lateral ao ínio. Corresponde, internamente, ao ângulo formado pela união dos seios occipital e transverso. No acesso supra e infratentorial são colocados orifícios de trépano acima e abaixo do ínio (pontos paratorculares superior e inferior) e abaixo e acima do astério (pontos pré-occipital e retrossigmóideo) para expor o seio transverso.

13. Ponto de interseção do sulco frontal superior e da sutura coronária ou ponto para punção do corno frontal (Fig 1,4) - O bregma é o ponto de 
união das suturas coronal e sagital; pode ser, geralmente, identificado pela palpação e encontra-se, aproximadamente, a $13 \mathrm{~cm}$ do násio. O ponto de interseção do sulco frontal superior e da sutura coronária localiza-se sobre a sutura coronária a $2 \mathrm{~cm}$ do bregma ${ }^{6}$. É o ponto de trepanação para punção do corno frontal do ventrículo lateral.

14. Ponto de junção dos sulcos frontal superior e pré-central $($ Fig 1,4$)$ - Encontra-se $2 \mathrm{~cm}$ atrás e $2 \mathrm{~cm}$ lateral ao bregma e corresponde, internamente, à junção dos sulcos frontal superior e pré-central. É o ponto mais posterior para abordagem do corno frontal do ventrículo lateral através do sulco frontal superior.

15. Ponto de união dos sulcos frontal inferior e pré-central ou do stefânio (Fig 1, 3) - Localiza-se no stefânio (ponto de união da sutura coronária e da linha temporal superior) e corresponde, internamente, à junção dos sulcos frontal inferior e précentral ${ }^{6}$. Nele é colocado o terceiro orifício da craniotomia pterional ${ }^{1}$.

16. Ponto coronal inferior (Fig 1, 3) - A extremidade inferior da sutura coronária faz parte do ptério (união das suturas esfenoparietal, coronária, escamosa, frontoesfenoidal e esfenotemporal), e situa-se a 3 $\mathrm{cm}$ da apófise orbitária externa. Encontra-se imediatamente à frente do sulco pré-central e corresponde à parte triangular do giro frontal inferior ${ }^{7,8,9}$. É o ponto de eleição no acesso pterional para abertura da fissura silviana. Em 1861, Broca7 identificou o centro de expressão da linguagem na parte opercular do giro frontal inferior e realizou os trabalhos pioneiros de topografia cranioencefálica. Ele determinou que as extremidades inferiores da sutura coronária e do sulco précentral distavam, aproximadamente, $10 \mathrm{~mm}$ e que entre ambos encontrava-se a parte opercular do giro frontal inferior (área de Broca). Broca ${ }^{8}$ foi o primeiro, em 1871, a realizar craniotomia orientada pela correlação de localização cerebral à topografia cranioencefálica, sendo esta a primeira vez que a localização de lesão intracraniana invisível foi seguida de intervenção neurocirúrgica. $O$ paciente apresentava quadro de afasia expressiva, indicando lesão da parte opercular do giro frontal inferior esquerdo. Através de orifício de trefina centrado imediatamente atrás da extremidade inferior da sutura coronária foi retirado um abscesso extradural.

17. Ponto inferior do sulco central (Fig 1, 3) Situa-se $3 \mathrm{~cm}$ posterior à sutura coronária. Sua união com o ponto superior do sulco central define o sul- co central e, portanto, o limite posterior do lobo frontal e da craniotomia frontal ${ }^{6-8}$.

18. Ponto superior do sulco pré-central (Fig $1,4)$ - Encontra-se $3 \mathrm{~cm}$ posterior ao bregma e marca o limite anteromedial do giro pré-central ${ }^{6-8}$. Aí é colocado o orifício de trépano posteromedial da craniotomia frontal quando não se deseja expor o giro pré-central.

19. Ponto superior do sulco central (Fig 1, 4) Localiza-se $5 \mathrm{~cm}$ posterior ao bregma e corresponde ao ponto superior do sulco central ${ }^{6-8,10}$. Define o limite póstero-medial do lobo frontal e da craniotomia frontal.

20. Ponto parieto-occipital (Fig 1, 5) - Situa-se $10 \mathrm{~mm}$ à frente de lambda (ponto de união das suturas sagital e lambdóide situado a, aproximadamente, $7 \mathrm{~cm}$ acima do ínio) e corresponde ao sulco parieto-occipital ${ }^{5,7,10}$. Define o limite ântero-medial da craniotomia occipital e o limite posteromedial da craniotomia parietal.

21. Ponto para punção do corno occipital (Fig $1,5)$ - Localiza-se $3 \mathrm{~cm}$ lateral ao lambda e nele é realizado o orifício de trépano para punção do corno occipital do ventrículo lateral.

22. Ponto intraparietal (Fig 1, 4) - Localiza-se $5 \mathrm{~cm}$ anterior ao lambda (ou $7 \mathrm{~cm}$ posterior ao bregma) e $4 \mathrm{~cm}$ lateral à linha médio-sagital. Corresponde à junção dos sulcos pré-central e intraparietal. É o ponto mais anterior para abordagem do átrio do ventrículo lateral através do sulco intraparietal.

\section{REFERÊNCIAS}

1. Yasargil MG. Microneurosurgery, vol 1. Stuttgart: Georg Thieme Verlag, 1984:220.

2. Al-Mefty O, Fox JL. Superolateral orbital exposure and reconstruction. Surg Neurol 1985;23:609-613.

3. Seeger W. Atlas of topographical anatomy of the brain and surrounding structures. Wien: Springer-Verlag, 1978:209.

4. Ribas GC. Estudo das relações topográficas das suturas lambdóide, occipitomastóidea e parietomastóidea com os seios transverso e sigmóide, e de trepanações da região. Tese de Doutorado. Faculdade de Medicima da Universidade de São Paulo. São Paulo, 1991.

5. Gusmão S. Determinação do limite anterolateral do lobo occipital. Arq Neuropsiquiatr 2002;60:41-46.

6. Gusmão S, Reis C, Silveira RL, Cabral G. Relações da sutura coronária com os sulcos da face súpero-lateral do lobo frontal: aplicações neurocirúrgicas. Arq Neuropsiquiatr. 2001;59:570-576.

7. Broca P. Sur les rapports anatomiques des divers points de la surface du crâne e des diverses parties des hémisphères cérébraux. Bull Soc d'Anthrop 1861;2:340-348.

8. Broca P. Sur la topographie cranio-cérébrale ou sur les rapportes anatomiques du crâne et du cerveau. Rev d'Anthrop 1876;5:193-248.

9. Rowland LP, Mettler FA. Relation between the coronal suture and cerebrum. J Comp Neurol 1948;89:21-40.

10. Seeger $W$. The microsurgical approaches to the target areas of the brain. Wien: Springer-Verlag, 1993:8-20. 